\title{
Microcalorimetric investigation of water vapor adsorption on silica gel
}

\author{
Hasan Demir · Moghtada Mobedi · Semra Ülkü
}

Received: 10 November 2010/ Accepted: 10 February 2011/Published online: 26 February 2011

(C) Akadémiai Kiadó, Budapest, Hungary 2011

\begin{abstract}
Water vapor adsorption on silica gel was investigated using Tian-Calvet-type microcalorimetry. Differential heat of adsorption data was obtained. The setup of microcalorimetry was used volumetric system to determine adsorption isotherms of water vapor-silica gel. The Langmuir model was used in the interpretation of the adsorption data. The Clausius-Clapeyron diagram was also given. Effective mass diffusivity of water vapor in the silica gel particle as a function of temperature was also determined. The silica gel, which was degassed under vacuum at $10^{-7}$ mbar and $120{ }^{\circ} \mathrm{C}$ for $18 \mathrm{~h}$, was found to adsorb $0.6,0.98,1.1,1.4,2,3.5,11,13$, and $14 \mathrm{wt} \%$ water vapor at $120,110,100,90,75,60,40,35$, and $30{ }^{\circ} \mathrm{C}$, respectively. The diffusivities of water vapor inside the silica gel for short- and long-range periods were described using kinetics data as a function of temperature in the Arrhenius form.
\end{abstract}

Keywords Microcalorimetry - Diffusivity · Silica gel-water pair $\cdot$ Heat of adsorption

H. Demir · S. Ülkü

Department of Chemical Engineering, Izmir Institute of Technology, 35430 Izmir, Turkey

M. Mobedi

Department of Mechanical Engineering, Izmir Institute of Technology, 35430 Izmir, Turkey

H. Demir $(\bowtie)$

Department of Chemical Engineering, Osmaniye Korkut Ata University, Karacaoglan Campus, 80000 Osmaniye, Turkey

e-mail: hasandemir@oku.edu.tr

\section{List of symbols}

$b \quad$ Langmuir constant

$C_{\infty} \quad$ Equilibrium concentration, $\mathrm{kg} \mathrm{m}^{-3}$

$D_{\text {eff }} \quad$ Effective diffusivity, $\mathrm{m}^{2} \mathrm{~s}^{-1}$

$D_{0} \quad$ Reference diffusivity, $\mathrm{m}^{2} \mathrm{~s}^{-1}$

$\Delta H_{\mathrm{st}} \quad$ Heat of vaporization, $\mathrm{kJ} \mathrm{kg}_{\mathrm{w}}^{-1}$

$\Delta H^{\mathrm{a}} \quad$ Integral heat of adsorption, $\mathrm{kJ} \mathrm{kg}^{-1}$

$\Delta \bar{h}^{\mathrm{a}} \quad$ Differential heat of adsorption, $\mathrm{kJ} \mathrm{mol}^{-1}$

$E \quad$ Diffusion activation energy, $\mathrm{J} \mathrm{mol}^{-1}$

$n \quad$ Eigen value

$n^{\mathrm{a}} \quad$ Amount of adsorbate mol kg $\mathrm{kg}^{-1}$

$P \quad$ Pressure, $\mathrm{kPa}$

$r_{\mathrm{p}} \quad$ Radius of adsorbent granule, $\mathrm{m}$

$R \quad$ Ideal gas constant, $\mathrm{J} \mathrm{mol}^{-1} \mathrm{~K}^{-1}$

$t \quad$ Time, s

$T \quad$ Temperature, $\mathrm{K}$

$W \quad$ Average adsorbate concentration, $\mathrm{kg}_{\mathrm{w}} \mathrm{kg}_{\mathrm{S}}^{-1}$

$W_{\mathrm{m}} \quad$ Monolayer adsorption coverage, $\mathrm{kg}_{\mathrm{w}} \mathrm{kg}_{\mathrm{S}}^{-1}$

$\bar{W}_{\mathrm{t}} \quad$ Average adsorption coverage at time $t, \mathrm{~kg}_{\mathrm{w}} \mathrm{kg}_{\mathrm{S}}^{-1}$

$W_{\infty} \quad$ Adsorbate concentration in equilibrium, $\mathrm{kg}_{\mathrm{W}} \mathrm{kg}_{\mathrm{s}}^{-1}$

\section{Introduction}

The adsorption of an adsorptive on an adsorbent depends on several factors such as crystalline structure of the adsorbent, pore dimensions, porosity, surface energy, surface area, types of adsorbate, etc. The properties of adsorbent-adsorbate pair are important for some areas for such as adsorption heat pumps that provide heating and cooling by utilizing thermal energy sources such as solar energy, geothermal energy, peak electricity, and waste heat from industrial processes [1-4]. The properties of 
adsorbent-adsorbate pair controls the performance criteria of designed adsorption heat pump. Therefore, in the selection of the appropriate adsorbent-adsorbate pair, properties of adsorbent-adsorbate pair, which are adsorption capacity, heat of adsorption, adsorptive diffusivity inside the adsorbent and adsorption kinetics and equilibria should be well known. Modeling of the adsorption behavior of adsorbent-adsorbate is helpful for determining Clausius-Clapeyron diagrams that are used for the assessment performance of the adsorption heat pump at operating conditions [5-7].

The adsorption capacity of adsorbents depends on the surface area of adsorbent, size of adsorptive, polarity features of adsorbent and adsorptive, shape and size of pores, etc. Aristov et al. [8] obtained sorption behavior of water vapor on Fuji RD silica gels which have $820 \mathrm{~m}^{2} \mathrm{~g}^{-1}$ BET surface areas and particle size between 0.3 and $1.0 \mathrm{~mm}$ using CAHN 2000 thermo-balance. They found the diffusivity values between $1.8 \times 10^{-11}$ and $6.3 \times 10^{-11} \mathrm{~m}^{2} \mathrm{~s}^{-1}$ for the temperatures of 30 and $65^{\circ} \mathrm{C}$, respectively. They also reported that apparent and effective diffusivities are slightly increased with the increasing adsorption temperature and the grain size of silica gel. Wang et al. [9] investigated the isotherm of silica gel-water pair. They used Type A silica gel having BET surface area of $716 \mathrm{~m}^{2} \mathrm{~g}^{-1}$ and 0.8-5-nm pore size. Wang et al. [9] calculated the heat of adsorption from the isotherms of water-silica gel pair as $2510 \mathrm{~kJ} \mathrm{~kg}^{-1}$ for temperature range from 303 to $358 \mathrm{~K}$.

Microcalorimetry is a powerful technique that can be used in various analytical research applications. Wang et al. [10] evaluated the antibacterial effect of benzoinum and styrax on Staphylococcus aureus growth, Bulanek et al. [11] investigated the heterogeneity of adsorption site of zeolite and Schabes and Sigstad [12] monitored the germination of soybean seed using microcalorimetric techniques.

Moise et al. [13] investigated water vapor adsorption on Ba-exchanged synthetic zeolite $\mathrm{X}$ and $\mathrm{Y}$ by microcalorimeter at 298 and $423 \mathrm{~K}$. Heat of adsorption of barium exchanged zeolite $\mathrm{Y}$ is higher than that of Ba-exchanged zeolite $\mathrm{X}$ for both the temperatures. Ozkan and Ülkü [14] have investigated water vapor adsorption on local clinoptilolite by Omnisorp 100cx volumetric apparatus. They investigated that the effects of outgasing temperature on the water vapor adsorption isotherms for clinoptilolite. The gradual increase in the amount adsorbed is observed with increasing outgasing temperature. Ülkü [15] determined heat of adsorption of water vapor-clinoptilolite as function of amount adsorbed. Janchen et al. [16] investigated the differential heat of adsorption of water vapor on zeolite, $\mathrm{AlPO}_{4}$ and $\mathrm{CaCl}_{2}$. They compared the differential heat of water vapor adsorption on zeolite and $\mathrm{CaCl}_{2}$ at $313 \mathrm{~K}$.
They found that different behaviors of heat curves of zeolite and $\mathrm{CaCl}_{2}$ indicate the different water vapor adsorption behaviors of zeolite and $\mathrm{CaCl}_{2}$ materials.

The goal of this study is to determine the properties of silica gel-water vapor which can later be used in an adsorption heat pump system. The adsorption capacity of silica gel at various temperatures, heat of adsorption, differential heat of adsorption, water vapor diffusivity inside the silica gel, adsorption kinetics and equilibria were investigated. The adsorption isotherms were modeled with the Langmuir relationship. The Clausius-Clapeyron diagram of the silica gel-water vapor pair was also obtained. All the experiments were done using Tian-Calvet-type microcalorimeter providing perfect outgasing conditions and insulation among silica gel and surrounding.

\section{Materials and methods}

The silica gel was supplied from Merck Co. The equivalent diameter of adsorbent granules varies between 3 and $5 \mathrm{~mm}$. The dimensions of silica gel particles were large since most of the adsorption heat pump system operates with granular adsorbent bed. BET surface area and average pore diameter of silica gel were determined as $626 \mathrm{~m}^{2} \mathrm{~g}^{-1}$ and 2.0-2.5 nm, respectively, at $77 \mathrm{~K}$ by $\mathrm{N}_{2}$ adsorption in ASAP2010 micromeritics. The samples were degassed for $24 \mathrm{~h}$ under vacuum $10^{-5}$ mbar at $120^{\circ} \mathrm{C}$.

The heats of adsorption of adsorbent were measured using Tian-Calvet-type microcalorimetry system which composed of microcalorimeter cell, stainless steel connection tubes, pressure transducers, thermocouples, data logger, and a computer with the specific software (Fig. 1). The adsorption isotherms were also obtained using this setup which can be used as a volumetric adsorption system. For preventing water condensation on the stainless steel tubes, they were heated and kept constant at $45{ }^{\circ} \mathrm{C}$ using electrical resistance. The system pressure was measured with MKS 121 Baratron pressure transducer from 0 to 100 mbar with an accuracy of $0.05 \%$ at reading and 0.01 resolutions. The leak rate of system is $5 \times 10^{-6}$ mbar s$^{-1}$. At operating pressure (30 mbar), the pressure system remains constant for 3 weeks which provides enough time for completing one experiment.

In the determination of the heat of adsorption, the experiments steps were performed by the following procedure:

1. 500-mg adsorbent (silica gel) was put into the sample vacuum cell. Particles were not imbricated.

2. Sample vacuum cell was connected to the system and the pressure test was employed for the detection of leakage. 


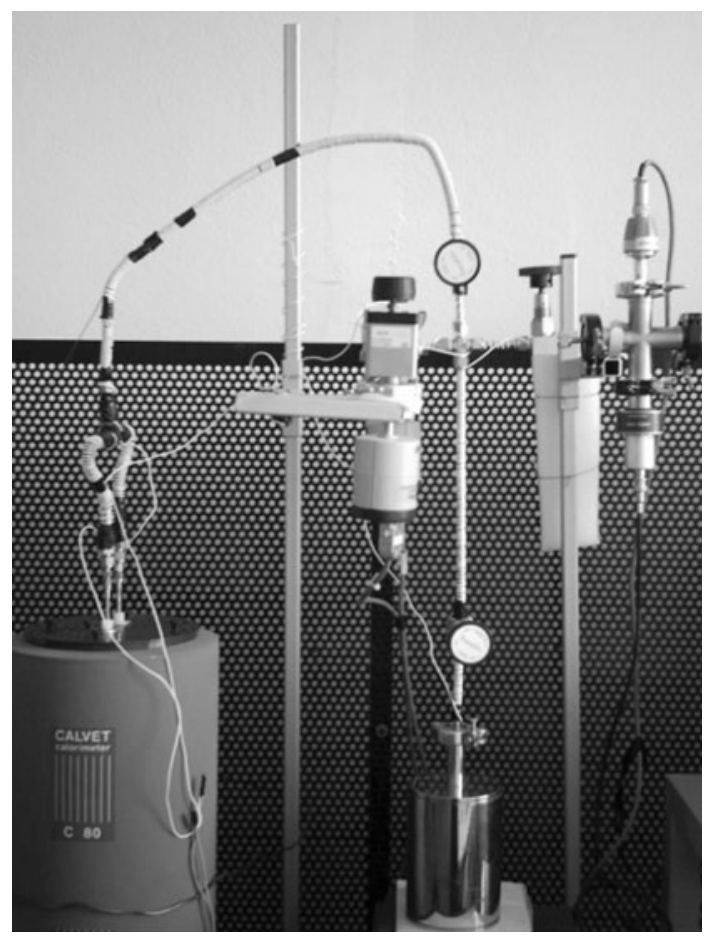

Fig. 1 Configuration of microcalorimetry

3. For degassing of the silica gel, sample cell was heated up to $120{ }^{\circ} \mathrm{C}$ inside the system with $1{ }^{\circ} \mathrm{C} \mathrm{min}-1$ under vacuum at $10^{-7}$ mbar. Meanwhile, stainless steel tubes were heated to $45^{\circ} \mathrm{C}$ by electrical resistance. The heating process for degassing proceeds for $18 \mathrm{~h}$ while the system is continuously evacuated.

4. The system was cooled down to the operating temperature $(30,35,40,60,75,90,100$, and 110) and kept at operating temperature to stabilize the system under vacuum at $10^{-7}$ mbar. This process takes for $6 \mathrm{~h}$.

5. After the system reaches to thermal equilibrium, one dose of water vapor was injected to the system. The generated heat due to the adsorption of water vapor was measured as $\mathrm{mV}$ and recorded against time.

6. The dose injection of water vapor was repeated after the cell reached to the thermal equilibrium. The pressure was increased gradually from 1 to 30 mbar.

After the 2nd step, these steps were repeated for different temperatures and data were collected.

\section{Results and discussions}

\section{Differential heat of adsorption}

Differential heat of adsorption for water vapor-silica gel pair can be calculated by integrating the area under the peak for each dose using SETSOFT software. Figure 2 depicts the differential heat of adsorption of water vaporsilica gel pair against the amount of coverage at 35 and $60{ }^{\circ} \mathrm{C}$. The variation of differential heat of adsorption can be divided into three regions for $35{ }^{\circ} \mathrm{C}$. First region is at lower coverage in which maximum differential heat of adsorption which is due to tightly bound water is observed. The second is at higher coverage between 2 and $10 \%$ of coverage, differential heat of adsorption can be seen as a plateau. After $11 \%$ coverage, the third section which is sharply declining one is observed. The zero coverage differential heat of adsorption is $140 \mathrm{~kJ} \mathrm{~mol}^{-1}$ at $35^{\circ} \mathrm{C}$. The increasing adsorption temperature decreased the heat of adsorption due to the reducing adsorbate-adsorbent interactions as seen in Fig. 2.

The differential heat of adsorption, measured by microcalorimetry, is a function of loading. The integral heat of adsorption can be obtained by integrating the differential heat of adsorption against amount of adsorbate at constant temperature as shown in Eq. 1 [17]. The integral heats of adsorption were calculated as 482.3 and $75.7 \mathrm{~kJ} \mathrm{~kg}^{-1}$ for the temperatures 35 and $60{ }^{\circ} \mathrm{C}$, respectively.

$\Delta H^{\mathrm{a}}=\int_{0}^{n^{\mathrm{a}}} \Delta \bar{h}^{\mathrm{a}} \mathrm{d} n^{\mathrm{a}} \quad$ (const. T)

Water vapor isotherms

The microcalorimeter setup is a volumetric system in which the amount of adsorptive in the system can be determined using ideal gas relation. It is assumed that at low pressure, the water vapor behaves as an ideal gas and the amount of adsorbed water on the silica gel was calculated using the ideal gas relationship and mass balance. Figure 3 illustrates the adsorption isotherm of water vapor on silica gel at $30,35,40,60,75,90,100,110$, and $120^{\circ} \mathrm{C}$. As can be seen in the figure, water vapor adsorption reached to equilibrium which can be interpreted as the completion of monolayer adsorption. The amount of adsorbate decreased with the increasing adsorption temperature. Silica gel adsorbed 0.6, 0.98, 1.1, 1.4, 2, 3.5, 11, 13 , and $14 \mathrm{wt} \%$ water vapor at $120,110,100,90,75,60$, 40,35 , and $30{ }^{\circ} \mathrm{C}$, respectively. The adsorption capacity of the adsorbent particles in the temperature range of $30-40{ }^{\circ} \mathrm{C}$ is higher than $10 \mathrm{~kg}_{\mathrm{w}} \mathrm{kg}_{\mathrm{S}}^{-1}$ while for the high temperature (above $75{ }^{\circ} \mathrm{C}$ ), the adsorption capacity was observed to be below $2 \mathrm{~kg}_{\mathrm{w}} \mathrm{kg}_{\mathrm{S}}^{-1}$ signifying high coverage of adsorbate in low temperature ranges.

BET surface area average pore diameter of the samples after water adsorption tests were measured as $509 \mathrm{~m}^{2} \mathrm{~g}^{-1}$ and $2.0-2.5 \mathrm{~nm}$, respectively. The BET surface area of silica gel was reduced for $18.7 \%$. Heat treatment during 
Fig. 2 Heat of adsorption versus water vapor loading curve at 35 and $60{ }^{\circ} \mathrm{C}$
Fig. 3 Isotherms of water vapor adsorption on silica gel
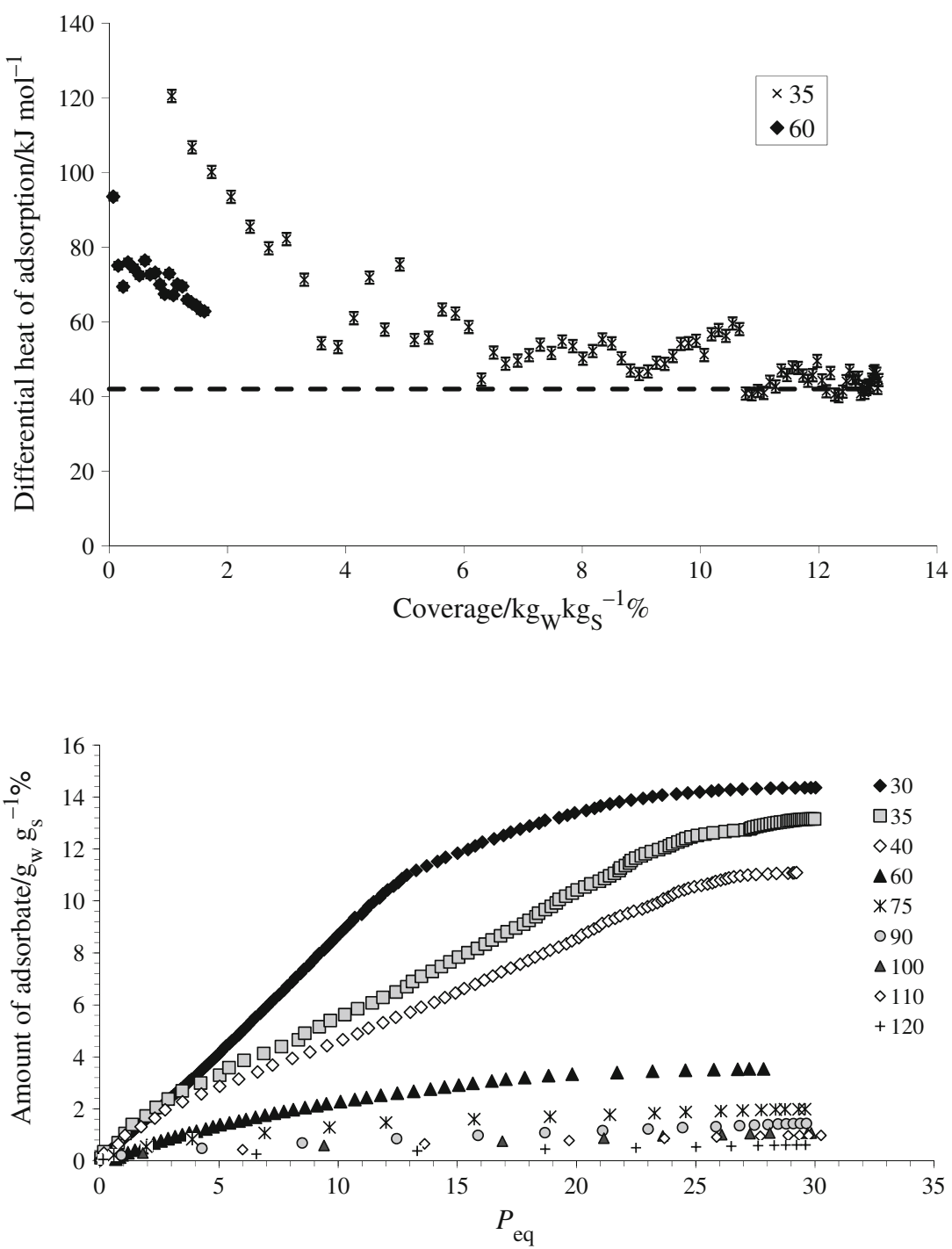

adsorption tests has affected the BET surface area of silica gel.

Isosteric heat of adsorption

Adsorption isotherms were represented by Langmuir model:

$W_{\text {langmuir }}=\frac{C_{\infty} W_{\mathrm{m}} b}{b C_{\infty}+1}$

where, $C_{\infty}$ can be calculated with the ideal gas relation at equilibrium pressure. The " $b$ " is Langmuir constant and $W_{\mathrm{m}}$ is monolayer coverage. The monolayer coverage and Langmuir constant can be found by plotting $C_{\infty} / W$ versus $C_{\infty}$ graph. The inverse slope gives monolayer coverage. The multiplication of the intercept with monolayer coverage gives inverse Langmuir constant. All Langmuir constants for each isotherms and regression coefficient of models are shown in Table 1 .
Table 1 Langmuir constants for different isotherms

\begin{tabular}{lrrl}
\hline Temperature $/{ }^{\circ} \mathrm{C}$ & \multicolumn{2}{c}{ Langmuir Constants } & $R^{2}$ \\
\cline { 2 - 3 } & $W_{\mathrm{m}}$ & $b$ & \\
\hline 30 & 34.5 & 5.69 & 0.9674 \\
35 & 29.5 & 5.14 & 0.8900 \\
45 & 25.1 & 5.03 & 0.8734 \\
60 & 5.9 & 11.71 & 0.9879 \\
75 & 2.5 & 24.10 & 0.9942 \\
90 & 2.8 & 6.89 & 0.9385 \\
100 & 2.5 & 1.51 & 0.9558 \\
110 & 1.5 & 11.47 & 0.9837 \\
120 & 1.3 & 5.59 & 0.9604 \\
\hline
\end{tabular}

The isosteric heat of adsorption was calculated by applying the Clausius-Clapeyron relationship (Eq. 3) to the equilibrium data. 
$\ln P=\frac{-\Delta H_{\mathrm{st}}}{R T}$

The Clausius-Clapeyron diagram (ln $P$ vs. $-1 / T)$, adsorption isosteres, was obtained from the experimental data as shown in Fig. 4. The Clausius-Clapeyron diagram was drawn until the $10 \%\left(\mathrm{~kg}_{\mathrm{w}} \mathrm{kg}_{\mathrm{s}}^{-1}\right)$ amount of adsorbate since the maximum amount of adsorbate can be obtained as $14 \%$ $\left(\mathrm{kg}_{\mathrm{w}} \mathrm{kg}_{\mathrm{s}}^{-1}\right)$ due to the low water vapor pressure dose and existing of closed pores inside the silica gel. The slope of ln $P$ versus $-1 / T$ curve gives the $\Delta H_{\mathrm{st}} / R$. The average isosteric heat of adsorption was calculated as $2644 \mathrm{~kJ} \mathrm{~kg}^{-1}$. Ben Amar et al. [18] reported that isosteric heat of adsorption for water vapor-silica gel pair is $2560 \mathrm{~kJ} \mathrm{~kg}^{-1}$ and Wang et al. [9] found the heat of adsorption from the isotherms of water-silica gel pair as $2510 \mathrm{~kJ} \mathrm{~kg}^{-1}$.

Water vapor diffusivity

Figure 5 shows the kinetics of water vapor adsorption on silica gel. As is seen, the total adsorption period is highly affected from the adsorption temperature. All silica gel particles inside the microcalorimeter cell were provided to have contact with the base of the cell. Hence, inside and outside temperatures of the silica gel particles were assumed to be same at the equilibrium. Equation 4 is the analytical solution of one-dimensional unsteady isothermal diffusion mass transfer for a spherical particle $[6,7]$.

$\frac{\bar{W}_{t}}{W_{\infty}}=1-\frac{6}{\pi^{2}} \sum_{n=1}^{\infty} \frac{1}{n^{2}} \exp \left[-\frac{n^{2} \pi^{2} D_{\text {eff }} t}{r_{p}^{2}}\right]$

where $r_{\mathrm{p}}$ indicates radius of particle, mass diffusivity is shown as $D_{\text {eff }}$ and equilibrium adsorbate concentration at the surface of particle presents as $W_{\infty}$.

The diffusivity of water vapor through the silica gel particles was calculated from the kinetics data using Eqs. 5 and 6 which are valid for short- and long-term regions and isothermal conditions. Equation 5 can be employed if $W_{t} / W_{\infty}<0.3$. The effective diffusivity for the short-term region can be found from the slope of $W_{t} / W_{\infty}$ versus $t^{1 / 2}$ plot.
Fig. 4 Clausius-Clapeyron diagram of water vapor on silica gel
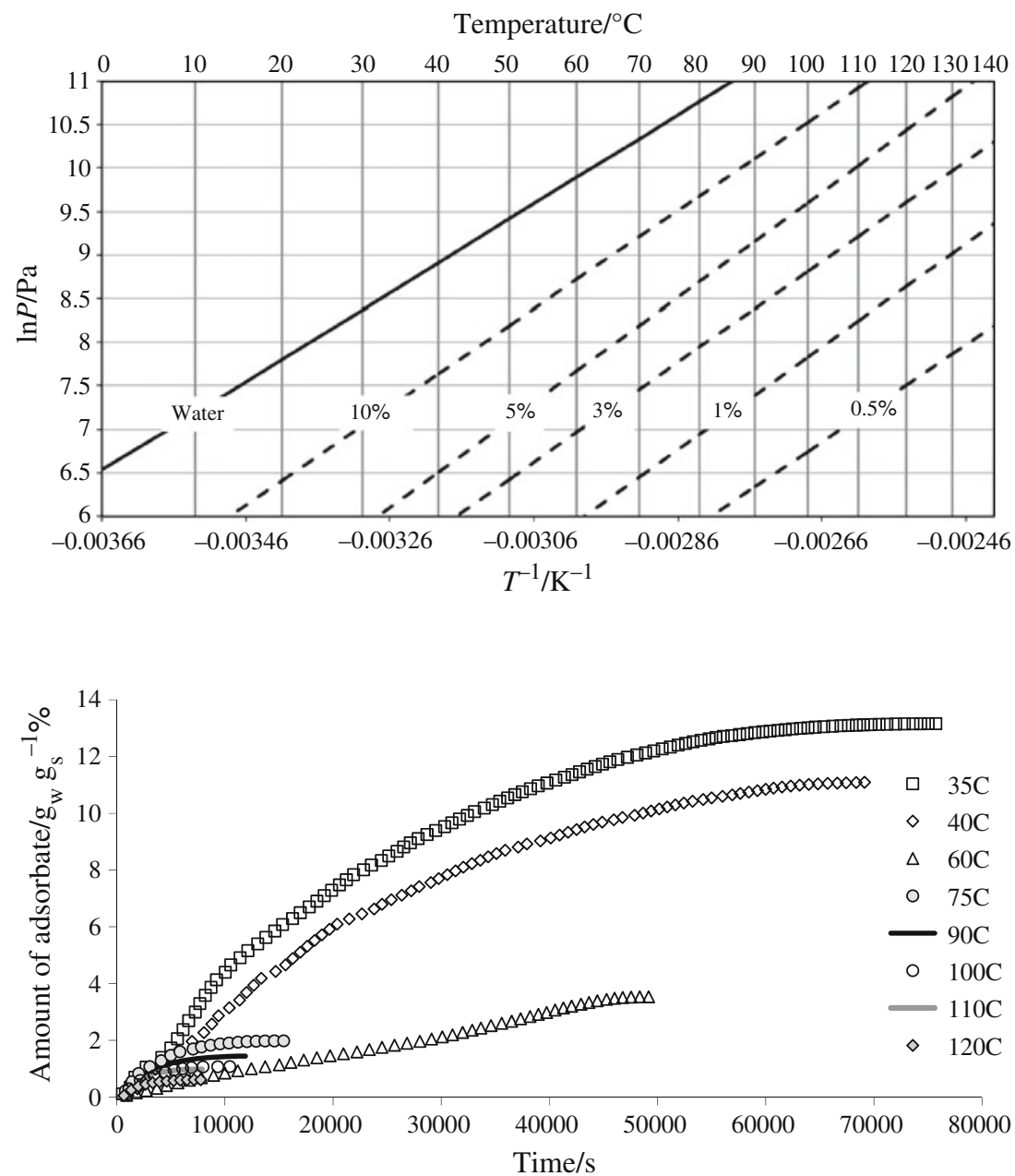

Fig. 5 Kinetics of water adsorption on silica gel 
$\frac{\bar{W}_{t}}{W_{\infty}}=\frac{6}{\sqrt{\pi}} \sqrt{\frac{D_{\text {eff }} t}{r_{p}^{2}}}$

Equation 6 can be employed if $W_{\mathrm{t}} / W_{\infty}>0.7$. The slope of $\ln \left(1-W_{t} / W_{\infty}\right)$ versus $t$ curve gives the effective diffusivity constant at that temperature for the long-term region.

$\frac{\bar{W}_{t}}{W_{\infty}}=1-\frac{6}{\pi^{2}} \exp \left[-\frac{\pi^{2} D_{\text {eff }} t}{r_{p}^{2}}\right]$

The effective diffusivities of water-silica gel pair were estimated for both short- and long-term regions and shown in Table 2. The equivalent radius of particle was taken as $1.6 \mathrm{~mm}$ in the calculation of effective diffusivities.

Figure 6 shows the variations of water vapor diffusivity on silica gel particle against the adsorption temperatures for short- and long-term regions. The water vapor diffusivity increased exponentially with the increasing adsorption temperature for both short- and long-term regions. The effective diffusivity was described as a function of temperature by applying Arrhenius equation on the experimental data.

Table 2 Water vapor diffusivities against temperature

\begin{tabular}{lll}
\hline Temperature $/{ }^{\circ} \mathrm{C}$ & $\begin{array}{l}\text { Short range } \\
\mathrm{D}_{\text {eff }} / \mathrm{m}^{2} \mathrm{~s}^{-1}\end{array}$ & $\begin{array}{l}\text { Long range } \\
\mathrm{D}_{\text {eff }} / \mathrm{m}^{2} \mathrm{~s}^{-1}\end{array}$ \\
\hline 30 & $3.92 \mathrm{E}-13$ & $2.52 \mathrm{E}-11$ \\
35 & $4.21 \mathrm{E}-12$ & $2.32 \mathrm{E}-11$ \\
40 & $4.76 \mathrm{E}-12$ & $2.83 \mathrm{E}-11$ \\
60 & $2.88 \mathrm{E}-12$ & $7.03 \mathrm{E}-11$ \\
75 & $7.21 \mathrm{E}-11$ & $1.26 \mathrm{E}-10$ \\
90 & $8.19 \mathrm{E}-11$ & $1.43 \mathrm{E}-10$ \\
100 & $1.04 \mathrm{E}-10$ & $2.35 \mathrm{E}-10$ \\
110 & $9.29 \mathrm{E}-11$ & $2.53 \mathrm{E}-10$ \\
120 & $2.28 \mathrm{E}-10$ & $2.80 \mathrm{E}-10$ \\
\hline
\end{tabular}

$D_{\text {eff }}=D_{0} e^{\left(-\frac{E}{R T}\right)}$

The $D_{0}$ indicates the reference diffusivity and $E\left(\mathrm{~J} \mathrm{~mol}^{-1}\right)$ is the activation energy. The gas constant indicates with $R\left(\mathrm{~J} \mathrm{~mol}^{-1} \mathrm{~K}^{-1}\right)$. The plot of $\ln \left(D_{\text {eff }}\right)$ versus $1 / T$ gives linear expression. The slope gives activation energy and reference diffusivity can be determined from the intercept. The effective diffusivities of water on silica gel in Arrhenius form for short- and long-term regions are shown in Eqs. 8 and 9 with 0.842 and 0.9678 regressions, respectively. Aristov et al. [8] found out diffusivity of water vapor on Fuji RD silica gel at different temperatures. The diffusivity values found by Aristov et al. [8] are between $1.8 \times 10^{-11}$ and $6.3 \times 10^{-11} \mathrm{~m}^{2} \mathrm{~s}^{-1}$ which are quite similar to our experimental (Table 2) data although the silica gel particle sizes and physical properties of two adsorbents are significantly different.

$D_{\text {eff }}=1.28 \times 10^{-2} \mathrm{e}^{\left(-\frac{57758}{R T}\right)}$

$D_{\text {eff }}=2.48 \times 10^{-6} \mathrm{e}^{\left(-\frac{29066}{R T}\right)}$

As mentioned above, the effective diffusivities of water vapor through the silica gel particle were obtained for short- and long-term regions of kinetic data using Eqs. 5 and 6 . The variation of adsorbate concentration ratio $\left(W_{\mathrm{t}} /\right.$ $W_{\infty}$ ) with time calculated by Eq. 4 based on long- and short-term diffusivity relations (Eqs. 8, 9) was plotted and compared with the experimental adsorbate concentration ratio as shown in Fig. 7. Figure $7 \mathrm{a}$ and $\mathrm{b}$ shows the comparison of experimental and theoretical data for the two temperatures of 35 and $90{ }^{\circ} \mathrm{C}$. At low temperature, theoretical amount of adsorbate calculated using short-range diffusivity value were close to the experimental values until the $W_{\mathrm{t}} / W_{\infty}<0.4$. For long-range diffusivities, theoretical amount of adsorbate approaches to the experimental values after the $W_{\mathrm{t}} / W_{\infty}>0.8$ which may be related to the non-spherical shape of the particles as it was also stated by Karger and Ruthven [6]. At high temperatures, theoretical amount of adsorbate which is determined by using both
Fig. 6 Variations of water vapor diffusivity on silica gel with temperatures for short term region and long term region

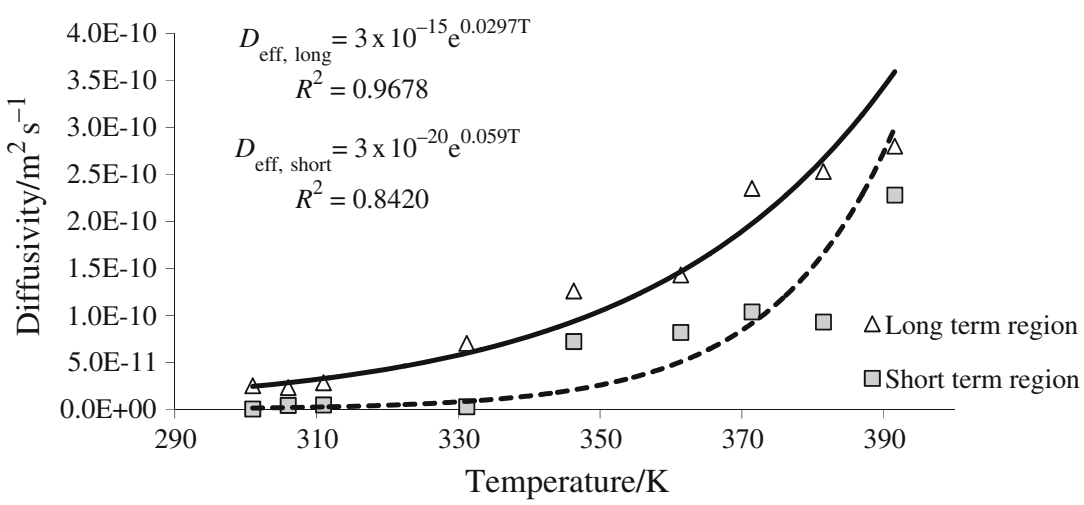


Fig. 7 Experimental and theoretical amount of adsorbate a $35^{\circ} \mathrm{C}$ and $\mathbf{b} 90{ }^{\circ} \mathrm{C}$
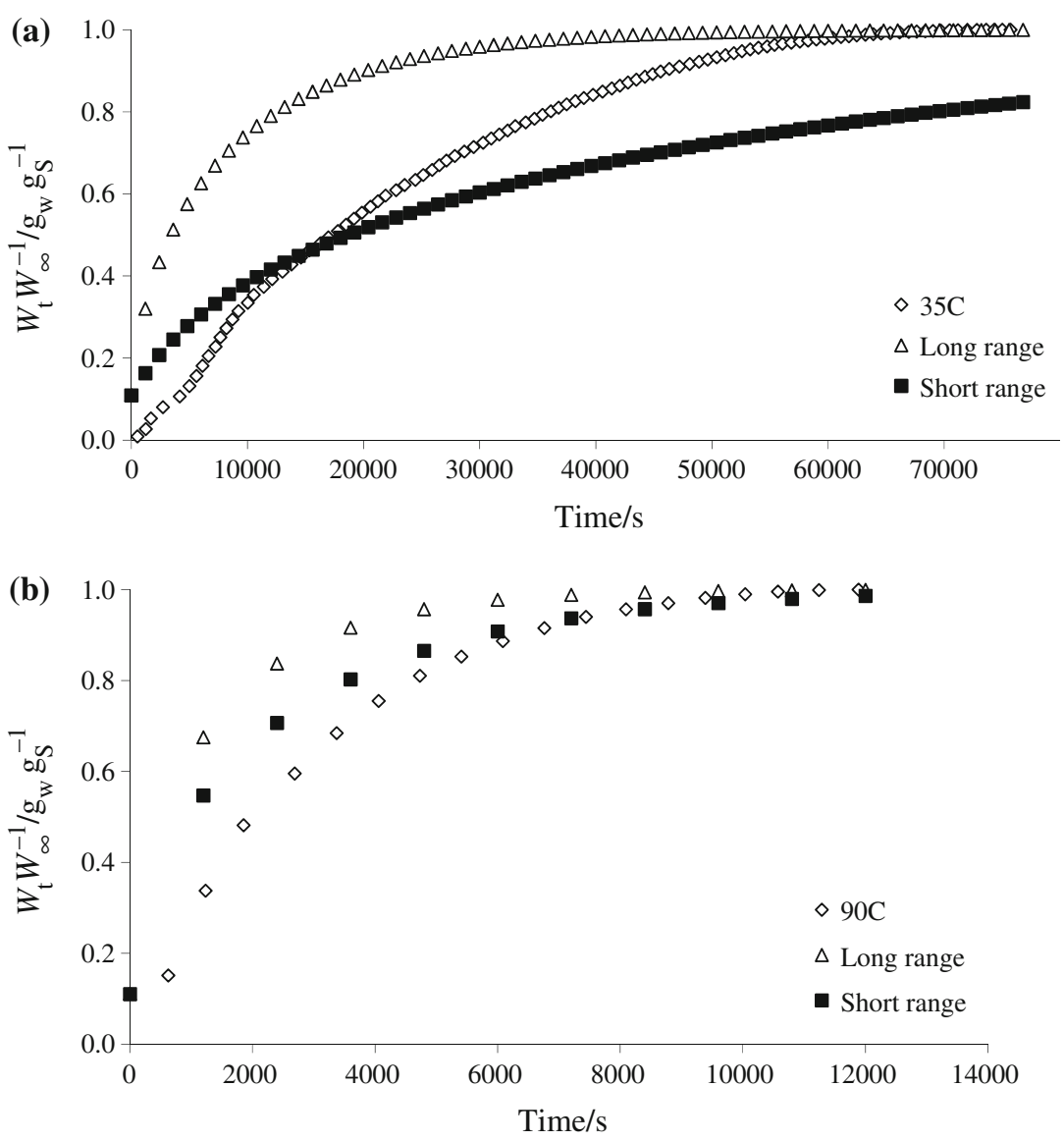

short- and long-range diffusivities very close to the experimental values for all $W_{\mathrm{t}} / W_{\infty}$ values. Temperature inside the particle is assumed uniform in the solution of Eq. 4; actually particle temperature will be increased due to heat of adsorption which will be influencing kinetics of adsorption and will be effective especially in the long-term region. Consequently, the short-range vapor diffusivity through the silica gel should be used for theoretically study.

\section{Conclusions}

An experimental study was performed to determine the isoster and isotherm diagrams, differential and isosteric heat of adsorption and mass diffusivity for water-silica gel pair. The maximum water adsorption capacity of silica gel which was degassed at was found as $14 \%$ for $30^{\circ} \mathrm{C}$ adsorption temperature. It was observed that the amount of adsorbed vapor decrease with the increase of adsorption temperature.

The differential heat of adsorption decreases with the increasing adsorption temperature. The maximum heat of adsorption was observed at the lower coverage due to the tightly bound water. The Clausius-Clapeyron diagram of water-silica gel pair was also drawn using the adsorption isotherm data. The isosteric heat of adsorption for silica gel-water vapor was found out $2644 \mathrm{~kJ} / \mathrm{kg}$ as an average.

The effective diffusivities were determined as function of temperature by using short-term region data and presented in Arrhenius form. Consequently, the ClausiusClapeyron diagram and short-term water vapor diffusivity are useful data for the adsorption heat pump application if this silica gel-water is selected as the adsorbent-adsorbate pair.

Acknowledgements Authors would like to thank to State Planning Organization of Turkey for their great financial supports to this project 2003K120690 (DPT-6).

\section{References}

1. Demir H, Mobedi M, Ülkü S. A review on adsorption heat pump: problems and solutions. Renew Sustain Energy Rev. 2008;12: 2381-403.

2. Ülkü S. Adsorption heat pumps. J Heat Recovery Sys. 1986;6: 277-84.

3. Ülkü S, Mobedi M. Adsorption in energy storage. Proc NATO Adv Stud Inst Energy Storage Syst Ser E Appl Sci. 1989;167:487-507.

4. Ülkü S. In: Yüncü H, Paykoç E, Yener Y, editors. Solar adsorption heat pumps. In: Solar energy utilization: fundamentals and applications. Netherlands: Martinus Nijkoff Publishers; 1987. 
5. Schnabel L, Henning MH. Experimental and simulation study on the kinetics of water vapour adsorption on different kinds of adsorptive material matrices. In: International sorption heat pump conference, Denver, USA, 2005.

6. Karger J, Ruthven DM. Diffusion in zeolites and other microporous solids. New York: Wiley-Interscience Pubs; 1992.

7. Ruthven DM. Principles of adsorption and adsorption processes. New York: Wiley-Interscience Pubs; 1984.

8. Aristov YI, Tokarev MM, Freni A, Glaznev SI, Restuccia G. Kinetics of water adsorption on silica Fuji Davison RD. Microporous Mesoporous Mater. 2006;96:65-71.

9. Wang X, Zimmermann W, Ng CK, Chakraboty A, Keller UJ. Investigation on the isotherm of silica gel-water systems TG and volumetric methods. J Therm Anal Calorim. 2004;76:659-69.

10. Wang J, Cheng D, Zeng N, Xia H, Fu Y, Yan D, Zhao Y, Xiao X. Application of microcalorimetry and principal component analysis: antibacterial evaluation of Benzoinum and Styrax on Staphylococcus aureus growth. J Therm Anal Calorim. 2010; 102:137-42.

11. Bulanek R, Frolich K, Frydova E, Cicmanec P. Study of adsorption sites heterogeneity in zeolites by means of coupled microcalorimetry with volumetry. J Therm Anal Calorim. doi: 10.1007/s10973-010-1108-y.
12. Schabes IF, Sigstad EE. Monitoring soybean seed germination by calorimetry. J Therm Anal Calorim. doi:10.1007/s10973-0101036-x.

13. Moise JC, Bellat JP, Methiever A. Adsorption of water vapor on $\mathrm{X}$ and $\mathrm{Y}$ zeolites exchanged with barium. Microporous Mesoporous Mater. 2001;43:91-101.

14. Ozkan FC, Ulku S. The effect of $\mathrm{HCl}$ treatment on water vapor adsorption characteristics of clinoptilolite rich natural zeolite. Microporous Mesoporous Mater. 2005;77:47-53.

15. Ulku S. Natural zeolites in energy storage and heat pumps. Surf Sci Catal. 1986;28:1047-54.

16. Janchen J, Ackermann D, Weiler E, Stach H, Brösicke W. Calorimetric investigation on zeolites, $\mathrm{AlPO}_{4}$ 's and $\mathrm{CaCl}_{2}$ impregnated attapulgite for thermo-chemical storage of heat. Thermochim Acta. 2005;434:37-41.

17. Myers AL. Thermodynamics of adsorption in porous materials. AIChE J. 2002;48:145-60.

18. Ben Amar N, Sun ML, Meunier F. Numerical analysis of adsorptive temperature wave regenerative heat pump. Appl Therm Eng. 1996;16:405-18. 